\title{
Physicochemical characteristics of dry aged beef from younger Nellore bulls slaughtered at different body weights
}

\author{
Rodrigo Augusto Cortêz Passetti ${ }^{1}$ (D) - Ivanor Nunes do Prado ${ }^{1} \cdot$ Francisco de Assis Fonseca de Macedo ${ }^{2}$. \\ Alfredo Jorge Costa Teixeira ${ }^{3}$. Claudia Andréa Lima Cardoso ${ }^{4} \cdot$ Gladston Rafael de Arruda Santos $^{2}$. \\ Camilo Azevedo Santos ${ }^{2}$
}

Received: 19 September 2018 / Accepted: 24 May 2019/Published online: 10June 2019

(C) Springer Nature B.V. 2019

\begin{abstract}
Reducing slaughter age can improve meat quality and reduce costs, while an ageing process can result in more standardized products. Thus, the objective of this paper was to measure the physicochemical characteristics of dry aged meat from younger Nellore bulls slaughtered at different body weights. Twenty-four Longissimus thoracis from young bulls (14 months of age) finished in a feedlot at body weights of 350, 400 and $450 \mathrm{~kg}$ were used. From each group $(N=8)$, samples were divided into three portions for 0,14 and 28 days of dry ageing. After the samples reached their dry aged period weight, $\mathrm{pH}$ and colour were measured. Next, water losses, shear force, the chemical composition and the fatty acids profile of the meat were measured. Reducing slaughter weight $(350 \mathrm{~kg}$ ) of young bulls did not affect meat tenderness but increased saturated fatty acids contents at day 1 of dry ageing. During the dry ageing process, drip loss increased, but thawing losses were reduced. Colour parameter was reduced by dry ageing and meat becomes darker, but meat tenderness was increased. Dry ageing increased the ash content. Dry ageing increased saturated fatty acid and reduced the monounsaturated and saturated fatty acid ratio (MUFA/SFA), but did not change the polyunsaturated fatty acids. Nellore young bulls (14 months) can be slaughtered with 400 or $450 \mathrm{~kg}$ without compromising physicochemical characteristics, while dry ageing improved meat tenderness but increased saturated fatty acids and changed meat colour.
\end{abstract}

Keywords Colour $\cdot$ Meat quality $\cdot$ Tenderness $\cdot$ Zebu

\section{Research highlights}

1. Younger bulls can be slaughtered earlier without compromising the physicochemical characteristics of meat.

2. Dry ageing improved meat tenderness from young bulls slaughtered with different body weight.

Rodrigo Augusto Cortêz Passetti

racpassetti@gmail.com

1 Department of Animal Science, State University of Maringá, Av. Colombo, n 5790, Maringá, Paraná 87020-900, Brazil

2 Department of Animal Science, Federal University of Sergipe, Aracaju, Sergipe, Brazil

3 Polytechnic Institute of Bragança, Campus Santa Apolónia, Bragança, Portugal

4 Department of Chemistry, State University of Mato Grosso do Sul, Dourados, Mato Grosso do Sul, Brazil

\section{Introduction}

The advantages of finishing animals earlier include a reduction of the slaughter age and a return on invested capital in the short term (da Silva-Marques et al. 2018; Luchiari 2000). Previous research has demonstrated that younger bulls finished at 12-14 months are more efficient during finishing than bulls finished at 24 months (Maher et al. 2004).

Meat colour is the first attribute that affects purchase decisions because consumers see and correlate a bright cherry red colour to freshness and wholesomeness, whereas a brown colour is considered undesirable (Mancini and Hunt 2005). The amount of subcutaneous fat is associated with slaughter weight, and a minimal amount of fat thickness is necessary to avoid the browning of superficial meat during chilling (Rotta et al. 2009). 
Tenderness is another important beef quality attribute (Grunert et al. 2004). Reducing slaughter age improves carcass characteristics and meat quality (Eiras et al. 2014). However, a minimum amount of subcutaneous fat thickness $(3.00 \mathrm{~mm})$ is necessary to guarantee meat tenderness and avoid muscle shortening due to the cold (Lawrie et al. 2005).

Fat content also plays a role in the intention to purchase meat, because the high consumption of saturated fatty acids (SFA) is associated with high serum cholesterol and lowdensity lipoproteins levels (LDL), which are risk factors for the incidence of cardiovascular diseases (Katan et al. 1994).

Dry ageing, a method of ageing in which meat is placed in cold stores with controlled temperature, relative humidity and air flow speed, can improve both meat tenderness and flavour (Hulánková et al. 2018); however, the impact of this process on meat characteristics still needs to be studied. For example, Kim et al. (2016) observed an increase in the number of metabolites responsible for meat flavour in dry aged meat, compared to conventional wet aged meat, but observed no differences in meat tenderness and water loss. Thus, the objective of this study was to evaluate the dry ageing process on the physicochemical characteristics of meat from younger Nellore bulls slaughtered at different body weights.

\section{Material and methods}

A total of 24 non-castrated Nellore steers (11 months of age), reared in the same feedlot conditions and in collective pens $\left(35 \mathrm{~m}^{2}\right.$ /animal), were used. The animals were distributed in a completely randomized design, in three treatments: $350 \mathrm{~kg}$, $400 \mathrm{~kg}$ or $450 \mathrm{~kg}$ of body weight at slaughter $(N=8$ per group).

To measure the subcutaneous fat thickness, ultrasound equipment (ALOKA $500 \mathrm{~V}$ ) with a linear transducer (17.2 cm wide, frequency of $3.5 \mathrm{MHz}$ ) and an acoustic coupler with an image capture system was placed perpendicular to the length of the Longissimus thoracis muscle (between the 12th and 13th ribs).

The young bulls were slaughtered in a commercial slaughterhouse following the usual practices of the Brazilian beef industry. Forty-eight hours later, after chilling, samples of the Longissimus thoracis muscle (between 6th and 13th thoracic vertebra) with bone were taken. The Longissimus thoracis muscle was subdivided into three equal parts $(2.0 \pm$ $0.2 \mathrm{~kg}$ ) for dry ageing for 0,14 and 28 days. The samples were identified and stored in plastic bags, then immediately transported to the laboratory.

Dry ageing was performed in a cold room with the daily control of temperature $\left(2 \pm 2{ }^{\circ} \mathrm{C}\right)$ and humidity $(75 \%)$ using a digital thermo-hygrometer (1566-1 J-Prolab $\left.{ }^{\circledR}\right)$. On days 0,14 and 28 of ageing, the meat weight, $\mathrm{pH}$ and colour were measured. Water loss was determined by the difference in the weight of the meat on days 0,14 and 28 . The $\mathrm{pH}$ was measured using a bayonet meat $\mathrm{pH}$ meter (HI 99163®, HANNA). Colour measurements were taken using a colorimeter (Minolta CR-400®) operating in the CIE system, in which $L^{*}$ stands for lightness, $a^{*}$ represents the intensity of the red colour and $b^{*}$ is the intensity of the yellow colour.

After reaching the appropriate ageing time, excess meat, fat and bone were removed, and the Longissimus thoracis fillets were weighed, vacuum packed, identified, immediately frozen and stored at $-18{ }^{\circ} \mathrm{C}$. To determine thawing losses, the samples were thawed in a cold chamber at $4 \pm 1{ }^{\circ} \mathrm{C}$ for $24 \mathrm{~h}$ and then weighed in a semi-analytical weighing machine. To determine cooking loss, the samples were previously defrosted for $24 \mathrm{~h}$ under refrigeration $\left(4^{\circ} \mathrm{C}\right)$, cut into 2.5 -cm-thick steaks and weighed. Next, they were wrapped in aluminium foil and cooked on a grill at $200^{\circ} \mathrm{C}$ until their geometric centre reached $72{ }^{\circ} \mathrm{C}$, which was monitored through a thermometer coupled to a digital reader. Upon reaching $72{ }^{\circ} \mathrm{C}$, the samples were taken off the grill, dried with absorbent paper and weighed. Cooking loss was calculated as the difference in the weight of the samples before and after cooking, expressed as a percentage.

Shear force was determined according to the WarnerBratzler shear force analysis protocol (Wheeler et al. 1997). The cooked steaks, previously used to determine cooking loss, were left to sit at room temperature $\left(20^{\circ} \mathrm{C}\right)$ for $30 \mathrm{~min}$. Using a digital paquimeter, brick-shaped cuts $(2.5 \mathrm{~cm}$ long, $1.0 \mathrm{~cm}$ diameter) were made according to the fibre orientation. The strength necessary to cut each sample transversally was measured with a texturometer (Stable Micro System TA-XT®) equipped with a Warner-Bratzler attachment, operating at a speed of $5 \mathrm{~mm} / \mathrm{s}$. The mean shear force of eight cuts from each sample represented the toughness value of each steak, expressed in kgf. For chemical analyses, the moisture, mineral matter, lipid, protein and collagen were determined according to the principle of near infrared spectroscopy (AOAC method 2007-04) with the equipment FoodScan ${ }^{\text {TM }}$.

For lipid composition, fat was extracted using the technique described by Bligh and Dyer (1959) with chloroformmethanol solution. Transesterification was performed according to method no. 5509 (ISO 2000), with $\mathrm{KOH} /$ methanol and $\mathrm{n}$-heptane. Thereafter, the methyl ester composition of the fatty acids was measured by high-resolution chromatography (Agilent 7890AGas Chromatograph ${ }^{\circledR}$ ) equipped with an auto sampler, a flame ionization detector at $240{ }^{\circ} \mathrm{C}$ (Agilent 5975CTAD Series GC®) and a fused-silica capillary column (100 m long, $0.25 \mathrm{~mm}$ internal diameter and $0.20 \mu \mathrm{m}$ film thickness; SP ${ }^{\circledR}-2560$ Capillary GC Column, SigmaAldrich). Fatty acid peaks were identified by comparison with the retention times of pure methyl ester standards (SigmaAldrich $\left.{ }^{\circledR}\right)$. Total saturated fatty acids, total monounsaturated fatty acids and total polyunsaturated fatty acids were computed. 
Generalized linear mixed models were fit to the experimental data using the GLIMMIX procedure in SAS (SAS v 9.4, SAS Institute, Cary, NC). Animal and Body Weight were modelled as categorical (CLASS) variables while Dry Ageing was included as a regression variable. To model repeated measurements in time (Dry Ageing) from the experimental animals, the RANDOM statement structured the variance-covariance matrix, where the "SUBJECT" was the Animal. The type of structure (VC, CS, CSH, AR(1), ARH(1), UN) was selected based on Bayesian information criterion. Body weight, Dry Ageing and the Body weight $\times$ Dry Ageing interaction were considered fixed, while Animal was included as a random factor in the models. Therefore, the models were "mixed." Differences in least squares means of body weight for each dry ageing period were adjusted by the Bonferroni test $(P<0.05)$.

\section{Results and discussion}

\section{Effect of slaughter weight}

The characteristics of young Nellore bulls finished in a feedlot are presented in Table 1. The animals were slaughtered after 84, 91 and 94 days in the feedlot. Interactions were observed for cut drip loss, shear force and arachidonic fatty acid (C20:4) between body weight (BW) and dry ageing (D) (Table 2). Subcutaneous fat thickness increased with the BW of the young bulls. Fat is the last tissue to be deposited, increasing after animals reach a certain degree of maturity (Owens et al. 1995). Animals at $350 \mathrm{~kg}$ presented a fat thickness that was lower than that recommended to avoid cold shortening (3.00$6.00 \mathrm{~mm}$; (Savell et al. 2005). A low-fat thickness is a major concern for producers when slaughtering younger pure zebu cattle, since even females slaughtered at $350 \mathrm{~kg}$ can present a fat thickness lower than $3 \mathrm{~mm}$ (Monteschio et al. 2017). In our study, young Nellore bulls slaughtered at 400 and $450 \mathrm{~kg}$ presented adequate subcutaneous fat thickness, similar to Nellore crossbreeds slaughtered at 16 months (Ornaghi et al. 2017).

No differences in $\mathrm{pH}$ was observed among body weight which were lower than 6.0 in day 1 of dry ageing. A pH higher

Table 1 Characteristics of Nellore young bulls finished in feedlot and slaughtered with different body weight

\begin{tabular}{|c|c|c|c|c|c|}
\hline & \multicolumn{3}{|c|}{ Body weight (B) } & \multirow[t]{2}{*}{ SEM } & \multirow[t]{2}{*}{$P$ value } \\
\hline & $350 \mathrm{~kg}$ & $400 \mathrm{~kg}$ & $450 \mathrm{~kg}$ & & \\
\hline$N$ (animals) & 8 & 8 & 8 & & \\
\hline Days in feedlot & 84 & 91 & 94 & 4.71 & 0.300 \\
\hline Final body weight (kg) & $363.25 \mathrm{C}$ & 401.75B & $454.00 \mathrm{~A}$ & 8.16 & 0.001 \\
\hline Fat thicknesses (mm) & $2.82 \mathrm{~B}$ & $3.20 \mathrm{~B}$ & $3.73 \mathrm{~B}$ & 0.09 & 0.001 \\
\hline
\end{tabular}

$\mathrm{A}, \mathrm{B}=$ differences in least square means adjusted to Bonferroni test when $P<0.05$ than 6.0 is a characteristic of DFD meat (Bernardes et al. 2007). According to Nassu et al. (2017), changes on meat colour are related to differences in $\mathrm{pH}$ between male and female Nellore crossbreds. However, in our study, the $\mathrm{pH}$ did not affect the colour of meat from animals slaughtered at the body weights of 350 to $450 \mathrm{~kg}$ in each dry aged period evaluated. The desired cherry red colour of meat is the major attribute of its appearance; it determines how consumers perceive meat quality and influences purchasing decisions (Faustman and Cassens 1990; Mancini and Hunt 2005).

An increase in body weight resulted on higher fat thickness and protected meat from cold shortening (Rotta et al. 2009). The lower fat thickness of $350 \mathrm{~kg}$ animals may increase the previously drip losses at the slaughter house and consequently those animals presented lower drip loss when samples were submitted to the dry ageing process. No differences in shear force were observed among body weights because young bulls were slaughtered earlier with 14 months. Age can negatively affect the composition and solubility of connective tissue, resulting in tougher meat (Wulf et al. 1996). However, according to Shackelford et al. (1991), to be classified as tender, Longissimus muscle must have less than $4.5 \mathrm{kgf}$ of shear force; thus, independent of body weight animals did not present a tender meat at day 1 of dry ageing. The chemical composition of the meat was not affected by body weight. The composition of lean meat is mainly water $(75 \%)$, in addition to protein $(20 \%)$ and fat (2\%), as well as some minor components, such as $2.5 \%$ for other substances like minerals and vitamins (Pedersen et al. 2003).

The increase of body weight resulted in the increase of saturated fatty acid lauric (C12), but also polyunsaturated fatty acids arachidonic (C20:4) linolenic (C18:3). As result, PUFA increased at day 1 of dry ageing, which could be explained by the higher protection of fat thickness during chilling through the prevention of the lipid oxidation of the meat (Rotta et al. 2009).

\section{Effect of dry ageing}

The weights of the dry ageing cuts were different due to the different location and size of the ribs (Table 2). Through the dry ageing process, the cuts decreased in weight due to water losses. Studies have reported that the dry ageing process results in an up to $10 \%$ loss of humidity (Warren and Kastner 1992). However, in our study, water losses were approximately 10 and $20 \%$ after dry ageing for 14 and 28 days, respectively. During dry ageing, temperature $\left(1-2{ }^{\circ} \mathrm{C}\right)$ and humidity ( 75 to $\left.85 \%\right)$ must be controlled in order to avoid spoilage (Kim et al. 2017; Perry 2012); if the air humidity is too low, there is a risk of greater weight loss, resulting from the evaporation of water (Hulánková et al. 2018). The $\mathrm{pH}$ increased over time, which could be explained by the loss of water. 
Table 2 Physicochemical characteristics of dry aged beef from Nellore young bulls slaughtered with different body weight

Expected values (least squares means) for the levels of body weight (BW) at each dry ageing (D) 1,14 and 28 days $n=24$

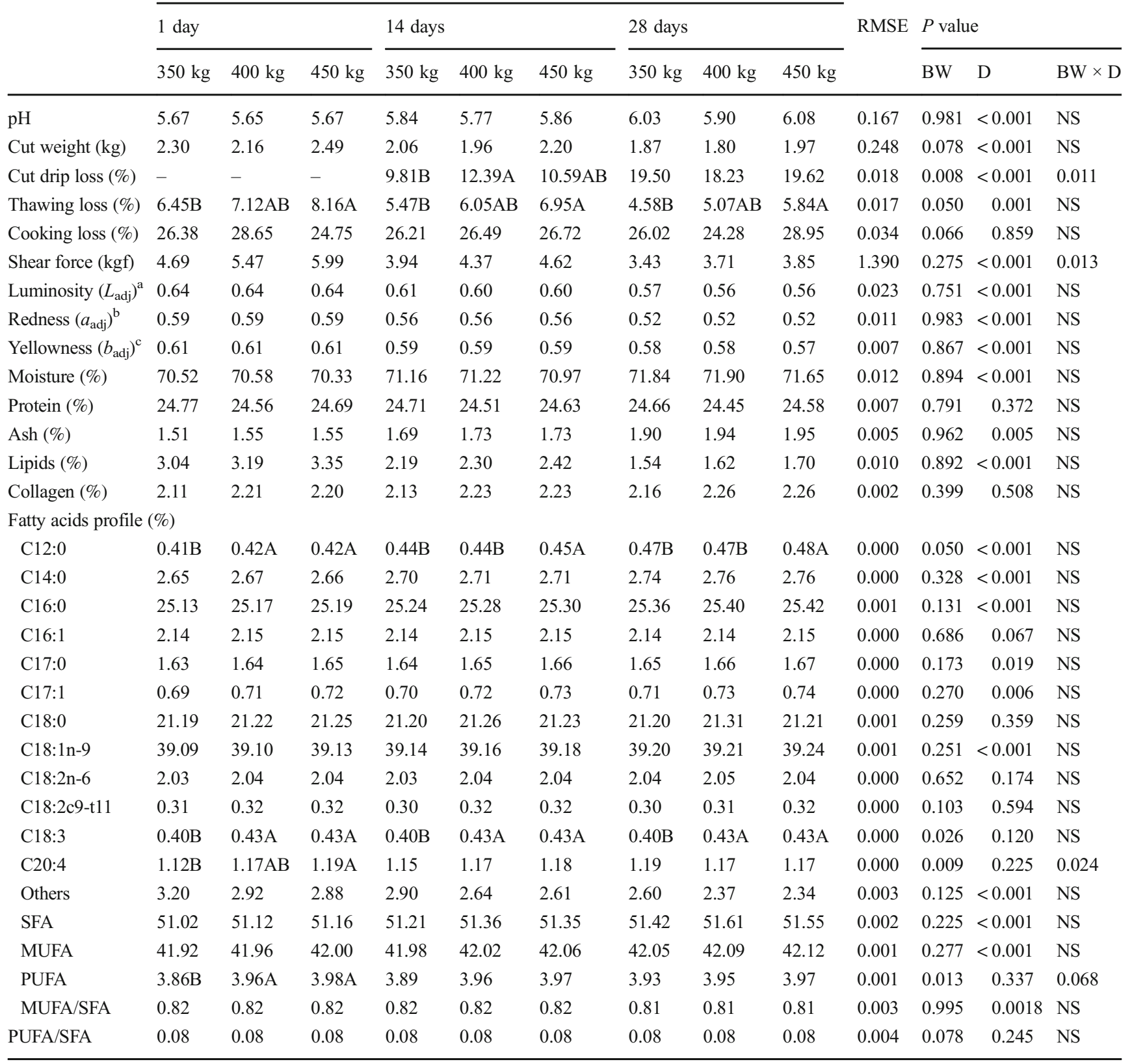

$\mathrm{A}, \mathrm{B}=$ differences in least square means of body weight for each dry ageing adjusted to the Bonferroni test when $P<0.05$

NS not significant, SFA saturated fatty acid, MUFA monounsaturated fatty acid, PUFA polyunsaturated fatty acid

${ }^{\mathrm{a}}\left(L_{\mathrm{adj}}\right)=(L+100) / 200$

${ }^{\mathrm{b}}\left(a_{\text {adj }}\right)(a+100) / 200$

${ }^{\mathrm{c}}\left(b_{a \mathrm{dj}}\right)(b+100) / 200$

The observed colour characteristics were lower than those from other studies (Eiras et al. 2014; Monteschio et al. 2017) because colour was measured from the exterior of the cut in order to evaluate the dry ageing process. All colour parameters reduced through the dry ageing process and meat becomes darker.

Dry ageing reduced thawing loss, but no differences were observed in cooking loss (Table 2). This could be explained by 
the higher drip loss for meat that was dry aged. Similar results were observed by Kim et al. (2017), who evaluated dry ageing and stepwise dry/wet ageing and observed similar thawing and cooking losses, but noted a higher drip loss for dry aged beef. The shear force of meat from young Nellore bulls was reduced by the dry ageing. Traditionally, dry ageing is performed for about 28-35 days, to reach a balance between tenderness, taste and juiciness (Perry 2012).

The meat chemical composition was influenced by the positions of cuts used for dry ageing (Table 2). The cut that was not dry aged had a higher lipid content, while the cuts that were dry aged had higher moisture and ash contents, which was not expected. Kim et al. (2017) used Logissimus thoracis and lumborun from both sides of carcasses and divided muscle samples into three sections to randomize the distribution of treatments. However, in our study, we had a limited number of animals; thus, we decided to use the same cut sections for only Longissimus thoracis. We expected to have more homogeneous samples and reduce bias for dry ageing. However, the higher lipid content for the non-dry aged beef cut section was higher, due to its more frontal position, which had more marbling. In general, as the fat content increases in meat, protein remains the same, while moisture is replaced by fat (Moreno-Indias et al. 2011). The only parameter in which a bias did not occur was the ash content, which increased with the dry ageing process.

The dry ageing process increased the majority of the saturated fat acids, with the exception of stearic (C18) acid. Dry ageing changed the monounsaturated profile by increasing oleic (C18:1n-9) and margaroleic (C17:1) acids, but no differences were observed in polyunsaturated fatty acids (Table 2). Bovine fat is about $48 \%$ saturated fat and $52 \%$ unsaturated fat (Rotta et al. 2009). Saturated fatty acids are less desirable, especially palmitic (C16:0) and myristic (C14:0) acids, which are correlated with higher incidences of cardiovascular disease (Jiménez-Colmenero et al. 2001). Dry ageing reduced the MUFA/SFA ratio, which was expected, and could be associated with the increase of lipid oxidation, which occurs when meat is aged (Huff-Lonergan and Lonergan 2005). Dry ageing did not influence the PUFA content. PUFA is important to human health, especially the CLA (C18:2 $c-9 t$-11), which have anticarcinogenic properties (Beam et al. 2000).

In conclusion, younger Nellore bulls can be slaughtered earlier with 14 months with 400 and $450 \mathrm{~kg}$ without compromising the $\mathrm{pH}$, colour and chemical composition of their meat; however, meat tenderness still needs to be improved by ageing process. The loss of water in the dry ageing impacted meat characteristics, especially by reducing the colour and increasing tenderness and saturated fatty acids. However, further studies are necessary to evaluate if these changes are perceptive by consumers and may influence their acceptance of the final product.
Acknowledgements The authors would like to thank the livestock enterprises that support us: the Oiteiros Farm for providing the animals used in the research and the Santa Cruz Farm owners for yielding the feedlot area to carry out the experiment.

The authors thank Timothy Schwinghamer, Agricultural Research Biostatistician from Agriculture and Agri-Food Canada, for his contributions to the statistical analyses.

Funding The current project was funded by the Brazilian Council for Research and Technological Development $(\mathrm{CNPq}$, process number 401458/2014-8). Trade names or commercial products in this publication are mentioned solely for the purpose of providing specific information and do not imply recommendations or endorsement by the Department of Animal Science, State University of Maringá, Maringá, Paraná, Brazil.

\section{Compliance with ethical standards}

Animals were cared for in accordance with acceptable practices and experimental protocols reviewed and approved by Animal Ethics Committee at the Federal University of Sergipe (protocol $n^{\circ}$ 04/2016).

Conflict of interest The authors declare that they have no conflicts of interest.

\section{References}

Beam, T.M. et al., 2000. Effects of amount and source of fat on the rates of lipolysis and biohydrogenation of fatty acids in ruminal contents, Journal of Dairy Science, 83, 2564-2573

Bernardes, M.M. et al., 2007. Carnes PSE (Pale, Soft, Exudative) e DFD (Dark, Firm, Dry) em lombo suíno numa linha de abate industrial, Ciência e Tecnologia de Alimentos, 27,

Bligh, E.G., and Dyer, W.J., 1959. A rapid method of total lipid extraction and purification, Canadian Journal of Biochemistry and Physiology, 37, 911-917

da Silva-Marques, R.P. et al., 2018. Effects of protein-energetic supplementation frequency on growth performance and nutritional characteristics of grazing beef cattle, Tropical animal health and production, 50, 495-501

Eiras, C.E. et al., 2014. Glycerine levels in the diets of crossbred bulls finished in feedlot: Carcass characteristics and meat quality, Meat Science, 96, 930-936

Faustman, C., and Cassens, R.G., 1990. The biochemical basis for discoloration in fresh meat: a review, Journal of Muscle Foods, 1, 217 243

Grunert, K.G., Bredahl, L., and Brunsø, K., 2004. Consumer perception of meat quality and implications for product development in the meat sector - a review, Meat Science, 66, 259-272

Huff-Lonergan, E., and Lonergan, S.M., 2005. Mechanisms of waterholding capacity of meat: The role of postmortem biochemical and structural changes, Meat Science, 71, 194-204

Hulánková, R. et al., 2018. The effect of dry aging on instrumental, chemical and microbiological parameters of organic beef loin muscle, LWT-Food Science and Technology, 89, 559-565

ISO, 2000. Animal and Vegetable Fats and Oils-Preparation of Methyl Esters of Fatty Acids. In: I.O.f. Standardization (ed), ISO 5509, 2000, (International Organization for Standardization,

Jiménez-Colmenero, F., Carballo, J., and Cofrades, S., 2001. Healthier meat and meat products: their role as functional foods, Meat Science, 59, 5-13

Katan, M.B., Zock, P.L., and Mensink, R.P., 1994. Effects of fats and fatty acids on blood lipids in humans: an overview, The American Journal of Clinical Nutrition, 60, 1017S-1022S 
Kim, Y.H., Kemp, R., and Samuelsson, L.M., 2016. Effects of dry-aging on meat quality attributes and metabolite profiles of beef loins, Meat Science, $111,168-176$

Kim, Y.H.B. et al., 2017. Effects of stepwise dry/wet-aging and freezing on meat quality of beef loins, Meat Science, 123, 57-63

Lawrie, R.A., Marcos, B., and Asuncion, E.Q., 2005. Ciencia de la carne, (Artmed, Spain)

Luchiari, A.F., 2000. Pecuária da carne bovina, São Paulo: A. Luchiari Filho,

Maher, S.C. et al., 2004. Variation in the eating quality of M. longissimus dorsi from Holstein-Friesian bulls and steers of New Zealand and European/American descent, and Belgian Blue x HolsteinFriesians, slaughtered at two weights, Livestock Production Science, 90, 271-277

Mancini, R.A., and Hunt, M.C., 2005. Current research in meat color, Meat Science, 71, 100-121

Monteschio, J.O. et al., 2017. Clove and rosemary essential oils and encapsuled active principles (eugenol, thymol and vanillin blend) on meat quality of feedlot-finished heifers, Meat Science, 130, 50 57

Moreno-Indias, I. et al., 2011. Differences on meat quality of local cattle breed from outermost EU zone vs. commercial, Journal of Applied Animal Research, 39, 328-333

Nassu, R. et al., 2017. Effect of the genetic group, production system and sex on the meat quality and sensory traits of beef from crossbred animals, Tropical Animal Health and Production, 49, 1289-1294

Ornaghi, M.G. et al., 2017. Essential oils in the diet of young bulls: Effect on animal performance, digestibility, temperament, feeding behaviour and carcass characteristics, Animal Feed Science and Technology, 234, 274-283

Owens, F.N. et al., 1995. Review of some aspects of growth and development of feedlot cattle, Journal of Animal Science, 73, 3152-3172
Pedersen, D.K. et al., 2003. Early prediction of water-holding capacity in meat by multivariate vibrational spectroscopy, Meat Science, 65, $581-592$

Perry, N., 2012. Dry aging beef, International Journal of Gastronomy and Food Science, 1, 78-80

Rotta, P.P. et al., 2009. The effects of genetic groups, nutrition, finishing systems and gender of Brazilian cattle on carcass characteristics and beef composition and appearance: a review, Asian-Australasian Journal of Animal Sciences, 22, 1718-1734

Savell, J.W., Mueller, S.L., and Baird, B.E., 2005. The chilling of carcasses, Meat Science, 70, 449-459

Shackelford, S.D. et al., 1991. An evaluation of tenderness of the longissimus muscle of Angus by Hereford versus Brahman crossbred heifers, Journal of Animal Science, 69, 171-177

Warren, K.E., and Kastner, C.L., 1992. A comparison of dry-aged and vacuum-aged beef strip loins, Journal of Muscle Foods, 3, 151-157

Wheeler, T.L. et al., 1997. A comparison of Warner-Bratzler shear force assessment within and among institutions, Journal of Animal Science, 75, 2423-2432

Wulf, D.M. et al., 1996. Effects of animal age, marbling score, calpastatin activity, subprimal cut, calcium injection, and degree of doneness on the palatability of steaks from limousin steers, Journal of Animal Science, 74, 569-576

Publisher's note Springer Nature remains neutral with regard to jurisdictional claims in published maps and institutional affiliations. 